\title{
Predictive factors of quality of life in temporal and extratemporal lobe epilepsy: association with affective temperament profiles and psychiatric comorbidities
}

\author{
Factores predictivos de la calidad de vida en la epilepsia del lóbulo temporal y \\ extratemporal: asociación con perfiles de temperamento afectivo y comorbilidades \\ psiquiátricas
}

Sehnaz BASARAN', Halil Ibrahim TAS²

\begin{abstract}
Background: Investigating predictive factors of reduced quality of life (QOL) of patients and their association with focal epilepsy can improve management and treatment strategies. Objective: This study aimed to investigate the relationship between affective temperaments, depression, anxiety, disease characteristics, and QOL and to explore the predictors of QOL in patients with temporal lobe epilepsy (TLE) and extratemporal lobe epilepsy (ETLE). Methods: A total of 50 patients with TLE, 51 patients with ETLE, and 70 controls were enrolled. Affective temperaments were evaluated using the Temperament Evaluation of Memphis, Pisa, Paris, and San Diego-Autoquestionnaire (TEMPS-A). QOL was assessed by the Short-Form Health Survey (SF-36). Beck Depression Inventory and Beck Anxiety Inventory were used to explore depression and anxiety severity, respectively. Results: Compared with the controls, patients with TLE and ETLE had significantly higher scores on all TEMPS-A scales, except on hyperthymic temperament. All the SF-36 subscale scores were lower in the TLE and ETLE groups. Linear regression analysis revealed that depressive symptoms, anxiety, depressive and irritable temperament, and seizure frequency were significant predictors of QOL in TLE. Patients with ETLE with temperamental disturbances, depressive symptoms, and polytherapy had a poorer QOL. Conclusions: Affective temperaments, psychiatric disorders, and clinical factors may predict impaired QOL in patients with TLE and ETLE. Further studies are needed to identify predictors of QOL in various epilepsy subtypes.
\end{abstract}

Keywords: Epilepsy; Temperaments; Quality of Life;Temporal Lobe; Epilepsy, Temporal Lobe.

\section{RESUMEN}

Antecedentes: Explorar los factores asociados y predictivos que reducen la calidad de vida en la epilepsia focal produce un efecto beneficioso en las estrategias de gestión y tratamiento. Objetivo: Investigar la relación entre temperamentos afectivos, depresión, ansiedad, características de la enfermedad y calidad de vida (QOL) y explorar los predictores de QOL en pacientes con epilepsia del lóbulo temporal (TLE) y epilepsia del lóbulo extratemporal (ETLE). Métodos: Se inscribieron un total de 50 pacientes con TLE, 51 pacientes con ETLE y 70 controles. Los temperamentos afectivos se evaluaron mediante el cuestionario de autoevaluación de Temperamento de Memphis, Pisa, París y San Diego (TEMPS-A). La calidad de vida se evaluó mediante la encuesta de salud de formato corto (SF-36). También se realizó a todos los participantes el Inventario de Depresión de Beck (BDI) y el Inventario de Ansiedad de Beck (BAI). Resultados: Los pacientes con TLE y ETLE tuvieron puntuaciones significativamente más altas en todas las escalas TEMPS-A que los controles, excepto la hipertimia . En la comparación de las puntuaciones del SF-36 dentro de cada grupo, todas las subescalas fueron más bajas en los pacientes con TLE y ETLE. El análisis de regresión lineal reveló que la depresión y la ansiedad, el temperamento depresivo e irritable y la frecuencia de las convulsiones fueron predictores significativos de la calidad de vida en el TLE. Además, los pacientes con ETLE con desequilibrios de temperamento afectivo, depresión comórbida y politerapia tenían una peor calidad de vida. Conclusiones: Los temperamentos afectivos, los trastornos psiquiátricos y los factores clínicos pueden predecir el deterioro de la calidad de vida en pacientes con TLE y ETLE. Se necesitan más estudios para descubrir los predictores de la calidad de vida en varios subtipos de epilepsia.

Palabras clave: Epilepsia; Temperamentos; Calidad de Vida; Lóbulo Temporal; Epilepsia del Lóbulo Temporal.

\footnotetext{
'Kocaeli Derince Education and Research Hospital, Department of Neurology, Kocaeli, Turkey.

${ }^{2}$ Canakkale Onsekiz Mart University Medicine Faculty, Department of Psychiatry, Canakkale, Turkey.

SB (D) https://orcid.org/0000-0001-9475-9664; HIT (D) https://orcid.org/0000-0001-5849-9068

Correspondence: Sehnaz Basaran; Email: basaransehnaz@yahoo.com.

Conflict of interest: There is no conflict of interest to declare.
}

Authors' contributions: SB, HIT: conceived and designed the experiments; SB: analyzed the data; SB, HIT: contributed with reagents, materials, and analysis; SB: wrote the paper.

Received on September 24, 2020; Received in its final form on March 09, 2021; Accepted on March 22, 2021. 


\section{INTRODUCTION}

Epilepsy is a chronic neurological disorder of the brain characterized by recurrent seizures that affects individuals of all ages ${ }^{1}$. Epidemiological studies have revealed that patients with epilepsy (PWE) have a higher incidence of psychiatric comorbidities than the general population ${ }^{2}$. Although there is no clear evidence, pathogenic mechanisms underlying neurobiological, iatrogenic, and psychosocial factors may cause mood disorders (MDs) in the course of epilepsy3.

Depending on the chronic and episodic nature of epilepsy, occurrence of unexpected seizures and adverse effects of antiseizure medicines (ASMs) negatively influence quality of life (QOL). In addition, stigmatization, low self-esteem, and social isolation are potential factors for poorer $\mathrm{QOL}^{4}$. Although decreased QOL in PWE is well established, its association with MDs in this group is often overlooked ${ }^{5}$. Previous studies have suggested that patients with temporal lobe epilepsy (TLE) are more likely to develop psychiatric disorders due to the role of the limbic system in regulating mood and behavior ${ }^{6,7}$. On the contrary, several authors failed to demonstrate the superiority of the temporal corticosubcortical network in the development of psychiatric comorbidities ${ }^{4.8}$. Thus, the predominance of psychiatric symptoms in TLE remains controversial.

Temperament is defined as an automatic emotional response to events based on the underlying biological and genetic tendencies of personality 9 . Akiskal et al. described five temperaments that can be measured by the Temperament Evaluation of Memphis, Pisa, Paris, and San Diego-Autoquestionnaire (TEMPS-A). According to this tool, affective temperaments can provide clues to the subclinical manifestations of $\mathrm{MDs}^{10}$.

To date, two studies have assessed affective temperaments in a population with mixed types of epilepsy using TEMPS-A $\mathrm{A}^{11,12}$. Therefore, this study aimed to evaluate 1) affective temperaments, 2) the relationship between temperaments, depressive symptoms, anxiety, disease characteristics, and QOL, and 3) possible predictors of QOL in patients with TLE and extratemporal lobe epilepsy (ETLE).

\section{METHODS}

\section{Participants}

We screened 101 adult patients with a diagnosis of focal epilepsy and follow-up duration of at least 2 years in our epilepsy outpatient clinic. Patients were evaluated by their medical records including seizure semiology, video electroencephalography (EEG) and/or ictal and interictal EEG analysis, and high-resolution 1.5 Tesla cranial magnetic resonance imaging (MRI). Patients with TLE and ETLE were classified according to the anatomical origin (epileptogenic focus originated from temporal or outside the temporal lobe, respectively), based on semiologic, electroencephalographic, and neuroimaging findings with the International League Against Epilepsy classification of focal epilepsies $(1989)^{13}$. All the valid and reliable scales were applied by an experienced psychiatrist. Patients with high psychopathological scores were referred to the liaison psychiatry unit of our hospital.

The control group consisted of seventy age- and sex-matched healthy volunteers. Individuals with a known psychiatric comorbidity, cognitive disorder and acute/chronic medical disease that could affect test performance were excluded.

This study was approved by Ethics Committee of Canakkale University (2011-KAEK-27/2018E.1800148473).

\section{Questionnaires}

Sociodemographic and clinical data were collected by face to face interview. TEMPS-A, Short Form Health Survey (SF-36), Beck Depression Inventory (BDI) and Beck Anxiety Inventory (BAI) were applied to all participants.

\section{TEMPS-A}

Affective temperaments were evaluated by the TEMPS-A questionnaire: a self-administered, Likert-type scale consisting of 110 items that measures five subdimensions as suggested by Akiskal et al.: depressive, cyclothymic, hyperthymic, irritable, and anxious temperaments ${ }^{10}$.

\section{$B D I$}

BDI is a 21-item self-report instrument that assesses the presence and severity of depressive symptoms in the past two weeks. Each item is rated on a 4-point Likert-type scale ranging from 0 to 3 . The total score ranges from 0 to 63; subjects with $\geq 16$ points are considered to have depression ${ }^{14}$.

\section{$B A I$}

BAI is used to assess anxiety levels and consists of 21 questions with a Likert scale ranging from 0 to 3 and raw scores ranging from 0 to $63^{15}$. Scores are categorized as minimal ( 0 to 7 ), mild ( 8 to 15 ), moderate (16 to 25 ), and severe anxiety ( 30 to 63 ).

\section{SF-36}

SF-36 consists of 8 subscales that assess QOL: physical functioning $(\mathrm{PF})$, role limitation due to physical problems (RP), mental health $(\mathrm{MH})$, role limitation due to emotional problems $(\mathrm{RE})$, social functioning $(\mathrm{SF})$, general health $(\mathrm{GH})$, vitality $(\mathrm{VT})$, and bodily pain (BP). All scores range from 0 to 100 and higher scores reflect better $\mathrm{QOL}^{16}$.

\section{Statistical analysis}

SPSS 17.0 (SPSS Inc., Chicago, IL, USA) was used for statistical analysis. Descriptive analysis was presented using mean \pm standard deviation or percentages and numbers. Categorical data were analyzed using the chi-square test. Clinical data were compared between groups using the independent sample t-test and Mann-Whitney U test for normally and non-normally 
distributed variables, respectively. All scores were compared among the three groups with one-way analysis of variance. For non-normally distributed data, Spearman correlation analysis was used to assess the relationship between TEMPS-A, BDI, BAI, clinical variables, and SF-36 subscales. Multiple linear regression analysis was performed to explore the predictive effect of temperaments, depressive symptoms, anxiety, and clinical variables on QOL. A p value less than 0.05 was considered statistically significant.

\section{RESULTS}

\section{Demographic and clinical characteristics}

There were no statistical difference between sociodemographic parameters among patients and controls. ETLE patients had significantly fewer seizures than TLE $(p=0.028)$ (Table 1).

\section{Comparison of TEMPS-A, BDI, BAI, and SF-36 scores}

Patients with TLE and ETLE had no significant differences in TEMPS-A categories. Depressive, cyclothymic, anxious, and irritable scores in TLE and ETLE were statistically higher than controls $(p<0.001)$. However, there were no significant difference in hyperthymic scores among the groups $(\mathrm{p}=0.628)$.

Compared to the control group, PWE had significantly higher BDI and BAI scores. No differences were found in BDI and BAI scores between the two patient groups. In addition, SF-36 subscales in TLE and ETLE patients were significantly lower than controls. There were no significant differences in SF-36 subscales among patient groups (Table 2).

\section{Correlations between SF-36 subscales, clinical variables, affective temperaments, BDI and BAI}

\section{Correlation analysis of patients with TLE}

SF-36 subscales scores, except for $\mathrm{MH}$, were negatively correlated with seizure frequency in TLE patients. Number of ASMs was negatively correlated with GH. Depressive, cyclothymic, and anxious temperament and BDI and BAI scores were negatively correlated with all SF-36 subscales. There was a positive correlation with hyperthymic temperament and $\mathrm{PF}$, $\mathrm{GH}$, and RE. Irritable temperament was negatively correlated with all subscales except SF (Table 3).

Table 1. Demographic and clinic characteristics of patients with TLE, ETLE and controls.

\begin{tabular}{|c|c|c|c|c|c|}
\hline & & TLE $(n=50)$ & $\operatorname{ETLE}(n=51)$ & Controls $(n=70)$ & $\mathrm{p}$ \\
\hline Age (years) & $39.02 \pm 10.53$ & $40.05 \pm 16.35$ & $36.91 \pm 9.88$ & 0.359 & \\
\hline Sex (male,\%) & $25(50.0)$ & $29(56.9)$ & $31(44.3)$ & 0.393 & \\
\hline Education (years) & $8.66 \pm 4.11$ & $8.21 \pm 3.33$ & $9.31 \pm 3.79$ & 0.274 & \\
\hline \multirow[t]{3}{*}{ Occupational status } & Unemployed & $7(14.0)$ & $6(11.8)$ & $2(2.9)$ & 0.183 \\
\hline & Employed & $33(66.0)$ & $38(74.5)$ & $56(80.0)$ & \\
\hline & Retired & $10(20.0)$ & $7(13.7)$ & $12(17.1)$ & \\
\hline \multirow[t]{3}{*}{ Marital status } & Single & $10(20.0)$ & $12(23.5)$ & $23(32.9)$ & 0.264 \\
\hline & Married & $39(78.0)$ & $39(76.5)$ & $45(64.2)$ & \\
\hline & Separated/divorced & $1(2.0)$ & $0(0.0)$ & $2(2.9)$ & \\
\hline Age of epilepsy onset (years) & $20.40 \pm 13.67$ & $24.39 \pm 17.50$ & & 0.205 & \\
\hline Disease duration (years) & $18.72 \pm 12.95$ & $15.76 \pm 12.49$ & & 0.246 & \\
\hline $\begin{array}{l}\text { Seizure frequency (past } 3 \\
\text { months) }\end{array}$ & $3.52 \pm 3.12$ & $2.35 \pm 2.84$ & & 0.028 & \\
\hline \multirow[t]{3}{*}{ Seizure type (n,\%) } & Simple focal & $2(3.9)$ & $1(1.9)$ & & 0.781 \\
\hline & Complex focal & $39(76.5)$ & $42(82.4)$ & & \\
\hline & $\begin{array}{l}\text { Secondarily } \\
\text { generalized }\end{array}$ & $9(19.6)$ & $8(15.7)$ & & \\
\hline \multirow[t]{3}{*}{ Seizure lateralization } & Left/ right & $20 / 15$ & $13 / 21$ & & \\
\hline & Bilateral & 3 & 1 & & \\
\hline & Undetermined & 12 & 16 & & \\
\hline \multirow[t]{2}{*}{ MRI } & Normal & 23 & 20 & & \\
\hline & Abnormal & 27 & 31 & & \\
\hline \multirow[t]{4}{*}{ Number of ASMs $(n, \%)$} & Monotherapy & $28(56.0)$ & $28(54.9)$ & & 0.691 \\
\hline & Bitherapy & $19(38.0)$ & $17(33.3)$ & & \\
\hline & Polytherapy & $3(6.0)$ & $5(9.8)$ & & \\
\hline & Without therapy & $0(0.0)$ & $1(2.0)$ & & \\
\hline
\end{tabular}

TLE:Temporal Lobe Epilepsy; ETLE: Extratemporal Lobe Epilepsy; ASMs: Antiseizure Medicines; MRI: Magnetic Resonance Imaging. 
Table 2. Comparison of TEMPS-A, SF-36, BDI and BAl scores among patients with TLE, ETLE and controls.

\begin{tabular}{|c|c|c|c|c|c|}
\hline & & $\operatorname{TLE}(n=50)$ & ETLE $(n=51)$ & Controls $(n=70)$ & $\mathrm{p}$ \\
\hline \multirow[t]{5}{*}{ TEMPS-A Scales } & Depressive & $10.74 \pm 5.37 \dagger$ & $8.88 \pm 4.13 \neq$ & $3.87 \pm 2.32$ & $<0.0001$ \\
\hline & Cylocthymic & $11.14 \pm 4.99 \dagger$ & $9.50 \pm 5.08 \ddagger$ & $4.32 \pm 2.90$ & $<0.0001$ \\
\hline & Anxious & $11.54 \pm 7.16 \dagger$ & $8.50 \pm 6.38 \neq$ & $2.57 \pm 2.65$ & $<0.0001$ \\
\hline & Hyperthymic & $7.40 \pm 4.79$ & $7.70 \pm 4.33$ & $6.98 \pm 3.81$ & 0.628 \\
\hline & Irritable & $6.24 \pm 4.17 \dagger$ & $5.39 \pm 3.27 \neq$ & $2.18 \pm 2.26$ & $<0.0001$ \\
\hline \multirow[t]{10}{*}{ SF-36 } & PF & $61.20 \pm 31.35 \dagger$ & $68.52 \pm 27.35 \neq$ & $90.50 \pm 14.52$ & $<0.0001$ \\
\hline & $\mathrm{RP}$ & $44.00 \pm 41.20 \dagger$ & $49.50 \pm 42.57 \neq$ & $89.64 \pm 20.18$ & $<0.0001$ \\
\hline & $\mathrm{BP}$ & $55.78 \pm 21.95 \dagger$ & $63.15 \pm 25.80 \ddagger$ & $85.77 \pm 14.06$ & $<0.0001$ \\
\hline & SF & $56.28 \pm 28.87 \dagger$ & $65.11 \pm 29.49 \neq$ & $83.55 \pm 14.20$ & $<0.0001$ \\
\hline & $\mathrm{GH}$ & $48.52 \pm 24.52 \dagger$ & $53.13 \pm 21.54 \ddagger$ & $74.24 \pm 13.09$ & $<0.0001$ \\
\hline & $\mathrm{RE}$ & $52.50 \pm 42.09+$ & $53.43 \pm 43.20 \neq$ & $90.38 \pm 22.63$ & $<0.0001$ \\
\hline & VT & $42.30 \pm 25.37 \dagger$ & $48.84 \pm 26.36 \neq$ & $71.07 \pm 22.55$ & $<0.0001$ \\
\hline & $\mathrm{MH}$ & $53.92 \pm 27.39+$ & $61.64 \pm 23.28 \neq$ & $75.88 \pm 12.12$ & $<0.0001$ \\
\hline & $\mathrm{BDI}$ & $23.7 \pm 15.3 \dagger$ & $18.72 \pm 13.23 \neq$ & $5.08 \pm 3.73$ & $<0.0001$ \\
\hline & BAl & $26.3 \pm 17.6 \dagger$ & $20.84 \pm 16.49 \ddagger$ & $6.24 \pm 4.94$ & $<0.0001$ \\
\hline
\end{tabular}

TLE:Temporal Lobe Epilepsy: ETLE: Extratemporal Lobe Epilepsy:TEMPS-A:Temperament evaluation of Memphis, Pisa, Paris and San Diego Auto-questionnaire; SF-36: Short Form Health Survey; PF: Physical functioning; RP: role limitation due to physical problems; BP: bodily pain; SF: social functioning; GH: general perception of health; RE: role limitation due to emotional problems; VT: vitality; MH: mental health; BDI: Beck Depression Inventory; BAI: Beck Anxiety Inventory. * $p<0.01$ for TLE vs. ETLE; ${ }^{\dagger} p<0.01$ for TLE vs. Controls; ${ }^{\ddagger} p<0.01$ for ETLE vs. Controls.

Table 3. Correlations between SF-36 subscale scores, clinical variables, affective temperaments, BDI and BAI in patients with TLE.

\begin{tabular}{|c|c|c|c|c|c|c|c|c|}
\hline & PF & $\mathrm{RP}$ & $\mathrm{BP}$ & SF & $\mathrm{GH}$ & $\mathrm{RE}$ & VT & MH \\
\hline $\begin{array}{l}\text { Seizure frequency/ } \\
\text { (past } 3 \text { months) }\end{array}$ & $-0.32 \star$ & $-0.572 \star \star$ & $-0.343 *$ & $-0.358 *$ & $-0.403 * \star$ & $-0.49 * \star$ & $-0.311 \star$ & -0.217 \\
\hline Age at disease onset & 0.019 & 0.049 & -0.076 & -0.018 & 0.058 & -0.031 & -0.046 & -0.099 \\
\hline Disease duration & -0.248 & -0.236 & -0.088 & -0.233 & -0.237 & -0.129 & -0.201 & -0.096 \\
\hline Number of ASMs & -0.149 & -0.122 & -0.213 & -0.22 & $-0.306^{\star}$ & -0.278 & -0.339 & -0.194 \\
\hline Depressive & $-0.606 * \star$ & $-0.434 * \star$ & $-0.544^{\star \star}$ & $-0.489 * *$ & $-0.629 * \star$ & $-0.499 * *$ & $-0.642 * \star$ & $-0.628 * *$ \\
\hline Cyclothymic & $-0.341 *$ & $-0.42 * \star$ & $-0.488 * \star$ & $-0.464^{\star *}$ & $-0.466^{\star \star}$ & $-0.446 * \star$ & $-0.541 * *$ & $-0.393 * *$ \\
\hline Hyperthymic & $0.338^{*}$ & 0.17 & 0.153 & 0.146 & $0.326^{*}$ & $0.313^{*}$ & 0.262 & 0.27 \\
\hline Irritable & -0.174 & $-0.285^{\star}$ & $-0.37 * \star$ & -0.261 & $-0.318 *$ & $-0.363^{* *}$ & $-0.463^{* \star}$ & $-0.335^{\star}$ \\
\hline Anxious & $-0.499 * *$ & $-0.451 * \star$ & $-0.53 * *$ & $-0.435^{\star \star}$ & $-0.638 * \star$ & $-0.531 * \star$ & $-0.712^{\star \star}$ & $-0.607 * \star$ \\
\hline $\mathrm{BDI}$ & $-0.619 * \star$ & $-0.429 * \star$ & $-0.589 * *$ & $-0.512 * \star$ & $-0.666^{\star \star}$ & $-0.523 * *$ & $-0.748 * \star$ & $-0.751 * *$ \\
\hline $\mathrm{BAl}$ & $-0.554 * *$ & $-0.488 * \star$ & $-0.661 * \star$ & $-0.585 * \star$ & $-0.681 * \star$ & $-0.523 * \star$ & $-0.752 * *$ & $-0.62 * *$ \\
\hline
\end{tabular}

${ }^{*} \mathrm{p}<0.05 ; * * \mathrm{p}<0.01$; PF: Physical functioning; RP: role limitation due to physical problems, BP: bodily pain; SF: social functioning; GH: general perception of health; RE: role limitation due to emotional problems; VT: vitality; MH: mental health;TEMPS-A: Temperament evaluation of Memphis, Pisa, Paris and San Diego Autoquestionnaire; BDI: Beck Depression Inventory; BAI: Beck Anxiety Inventory; TLE: Temporal Lobe Epilepsy; ASMs: Antiseizure medicines; SF-36: Short Form Health Survey.

\section{Correlation analysis of patients with ETLE}

Number of ASMs were negatively correlated with SF-36 subscales except PF and MH. Depressive and anxious temperament and BDI scores were negatively correlated with all SF-36 subscale. Cyclothymic temperament, irritable temperament, and BAI scores, were negatively correlated with all SF-36 subscales, except MH, RE, and VT, respectively. Hyperthymic temperament scores were positively correlated with PF, GH, $\mathrm{MH}$, and VT (Table 4).

\section{Results of multiple linear regression analyses}

\section{Patients with TLE}

VT ( $66.8 \%$ of the variance, $\mathrm{R}=0.830$ ) and $\mathrm{GH}$ ( $54.8 \%$ of the variance, $\mathrm{R}=0.740$ ) were significantly correlated with $\mathrm{BAI}$ and depressive temperament. $\mathrm{MH}$ ( $55.7 \%$ of the variance, $\mathrm{R}=0.752$ ) was negatively correlated with BDI. BP ( $52.1 \%$ of the variance, $\mathrm{R}=0.735$ ) was significantly correlated with BAI and depressive temperament. $\mathrm{PF}$ ( $45.8 \%$ of the variance, $\mathrm{R}=0.701$ ) was 
correlated with depressive temperament, BAI and irritable temperament. $\mathrm{RP}$ (44.7\% of the variance, $\mathrm{R}=0.685$ ) was significantly correlated with seizure frequency and BAI. SF (35.1\% of the variance, $\mathrm{R}=0.604$ ) was significantly correlated with BAI. $\mathrm{RE}$ ( $32.5 \%$ of the variance, $\mathrm{R}=0.593$ ) was significantly correlated with anxious temperament and seizure frequency.

These results suggest that TLE patients with higher scores on depressive temperament, irritable temperament, BDI and BAI and increased seizure frequency had a poorer QOL.

\section{Patients with ETLE}

The MH subscale of the SF-36 was strongly correlated with BDI, hyperthymic and irritable temperaments with $52.9 \%$ of the variance explained $(\mathrm{R}=0.747)$. The SF subscale of the SF-36 test ( $45.5 \%$ of the variance, $\mathrm{R}=0.682$ ) was significantly correlated with anxious temperament. In addition, PF $(37.8 \%$ of the variance, $\mathrm{R}=0.416$ ) was significantly correlated with BDI and anxious and hyperthymic temperaments. In addition, the BP subscale ( $34.3 \%$ of the variance, $\mathrm{R}=0.586$ ) was significantly correlated with depressive temperament. The RP subscale was significantly correlated with anxious temperament and number of ASMs, with $34 \%$ of the variance explained ( $R=0.583)$. VT (31.8\% of the variance, $\mathrm{R}=0.588$ ) was significantly correlated with anxious and hyperthymic temperaments. RE was significantly correlated with anxious temperament (29.8\% of the variance, $\mathrm{R}=0.558)$. GH ( $24.2 \%$ of the variance, $\mathrm{R}=0.522)$ was negatively correlated with depressive and hyperthymic temperaments. These results indicated that receiving polytherapy, temperamental disturbances and comorbid depressive symptoms predict QOL in patients with ETLE. Table 5 outlines the statistically significant results.

Table 4. Correlations between SF-36 subscale scores, clinical variables, affective temperaments, BDI and BAI in patients with ETLE.

\begin{tabular}{|c|c|c|c|c|c|c|c|c|}
\hline & PF & RP & BP & SF & $\mathrm{GH}$ & $\mathrm{RE}$ & VT & $\mathrm{MH}$ \\
\hline $\begin{array}{l}\text { Seizure frequency/ } \\
\text { (past } 3 \text { months) }\end{array}$ & 0.009 & -0.077 & -0.157 & -0.156 & -0.119 & 0.019 & -0.004 & -0.117 \\
\hline Age at disease onset & -0.141 & -0.165 & -0.195 & 0.052 & -0.245 & -0.182 & -0.103 & 0.262 \\
\hline Disease duration & -0.175 & -0.176 & -0.104 & -0.202 & 0.003 & -0.056 & -0.035 & -0.114 \\
\hline Number of ASMs & -0.177 & $-0.375 * \star$ & $-0.304^{\star}$ & $-0.345^{\star}$ & $-0.284^{\star}$ & $-0.309 *$ & $-0.347 \star$ & -0.276 \\
\hline Depressive & $-0.493 \star \star$ & $-0.433 * \star$ & $-0.579 * *$ & $-0.503 * \star$ & $-0.481 * \star$ & $-0.333^{\star}$ & $-0.351^{\star}$ & $-0.380 * \star$ \\
\hline Cyclothymic & $-0.47 \star \star$ & $-0.473 * \star$ & $-0.406 * \star$ & $-0.472 * \star$ & $-0.349 *$ & $-0.406 * \star$ & $-0.332 *$ & -0.236 \\
\hline Hyperthymic & $0.316^{\star}$ & 0.108 & 0.196 & 0.144 & $0.375 * \star$ & 0.035 & $0.314^{\star}$ & $0.456^{* *}$ \\
\hline Irritable & $-0.307 \star$ & $-0.310 *$ & $-0.317 \star$ & $-0.405^{\star \star}$ & $-0.319 *$ & -0.178 & $-0.358 * \star$ & $-0.429 * *$ \\
\hline Anxious & 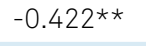 & $-0.555^{\star \star}$ & $-0.553 * \star$ & $-0.626^{* *}$ & $-0.384 * *$ & $-0.643 * *$ & $-0.472^{* *}$ & $-0.400 * *$ \\
\hline BDI & $-0.552 * \star$ & $-0.521 * \star$ & $-0.516^{\star \star}$ & $-0.458 * \star$ & $-0.464 * \star$ & $-0.509 * *$ & $-0.398 * \star$ & $-0.481 * \star$ \\
\hline BAl & $-0.423 * *$ & $-0.559 * *$ & $-0.511 * \star$ & $-0.441 * \star$ & $-0.343^{\star}$ & $-0.470 * \star$ & -0.418 & $-0.294^{\star}$ \\
\hline
\end{tabular}

${ }^{*} \mathrm{p}<0.05 ;{ }^{*} \mathrm{p}<0.01$; PF: Physical functioning; RP: role limitation due to physical problems; BP: bodily pain; SF: social functioning; GH: general perception of health; RE: role limitation due to emotional problems; VT: vitality; MH: mental health; TEMPS-A: Temperament evaluation of Memphis, Pisa, Paris and San Diego Auto-questionnaire; BDI: Beck Depression Inventory; BAI: Beck Anxiety Inventory; ETLE: Extratemporal Lobe Epilepsy; ASMs: Antiseizure medicines; SF36: Short Form Health Survey.

Table 5. Multiple linear regression analysis for SF-36 subscale scores in patients with TLE and ETLE.

\begin{tabular}{|c|c|c|c|c|c|c|}
\hline & $\mathrm{R}$ & Adj R2 & & $\beta$ & St coeff. $\beta$ & $\mathrm{p}$ \\
\hline \multicolumn{7}{|l|}{ Patients with TLE } \\
\hline PF & 0.701 & 0.458 & Depressive & -3.230 & -0.553 & 0.000 \\
\hline & & & $\mathrm{BAl}$ & -0.716 & -0.401 & 0.003 \\
\hline & & & Irritable & 2.622 & 0.349 & 0.009 \\
\hline $\mathrm{RP}$ & 0.685 & 0.447 & Seizure frequency & -6.115 & -0.464 & 0.000 \\
\hline & & & $\mathrm{BAl}$ & -0.928 & -0.396 & 0.001 \\
\hline $\mathrm{BP}$ & 0.735 & 0.521 & $\mathrm{BAl}$ & -0.655 & -0.525 & 0.000 \\
\hline & & & Depressive & -1.252 & -0.306 & 0.012 \\
\hline SF & 0.604 & 0.351 & BAI & -0.992 & -0.604 & 0.000 \\
\hline $\mathrm{GH}$ & 0.740 & 0.548 & BAl & -0.591 & -0.482 & 0.000 \\
\hline & & & Depressive & -1.446 & -0.361 & 0.003 \\
\hline $\mathrm{RE}$ & 0.593 & 0.325 & Anxious & -3.053 & -0.429 & 0.001 \\
\hline & & & Seizure frequency & -4.050 & -0.301 & 0.018 \\
\hline
\end{tabular}




\begin{tabular}{|c|c|c|c|c|c|c|}
\hline & $\mathrm{R}$ & Adj R2 & & $\beta$ & St coeff. $\beta$ & $\mathrm{p}$ \\
\hline $\mathrm{VT}$ & 0.830 & 0.668 & $\mathrm{BAl}$ & -0.539 & -0.173 & 0.002 \\
\hline & & & Depressive & -1.481 & 0.559 & 0.011 \\
\hline $\mathrm{MH}$ & 0.752 & 0.557 & $\mathrm{BDI}$ & -1.344 & -0.752 & 0.000 \\
\hline \multicolumn{7}{|l|}{ Patients with ETLE } \\
\hline PF & 0.416 & 0.378 & $\mathrm{BDI}$ & -0.735 & -0.356 & 0.011 \\
\hline & & & Anxious & -1.259 & -0.294 & 0.033 \\
\hline & & & Hyperthymic & 1.544 & 0.245 & 0.035 \\
\hline $\mathrm{RP}$ & 0.583 & 0.340 & Anxious & -3.207 & -0.481 & 0.000 \\
\hline & & & Number of ASMs & -14.902 & -0.246 & 0.045 \\
\hline $\mathrm{BP}$ & 0.586 & 0.343 & Depressive & -3.656 & -0.586 & 0.000 \\
\hline SF & 0.682 & 0.455 & Anxious & -3.150 & -0.682 & 0.000 \\
\hline $\mathrm{GH}$ & 0.522 & 0.242 & Depressive & -1.966 & -0.377 & 0.005 \\
\hline & & & Hyperthymic & 1.379 & 0.278 & 0.034 \\
\hline $\mathrm{RE}$ & 0.558 & 0.298 & Anxious & -3.777 & -0.558 & 0.000 \\
\hline $\mathrm{VT}$ & 0.588 & 0.318 & Anxious & -2.029 & -0.492 & 0.000 \\
\hline & & & Hyperthymic & 1.847 & -0.304 & 0.012 \\
\hline $\mathrm{MH}$ & 0.747 & 0.529 & $\mathrm{BDI}$ & -0.516 & -0.293 & 0.014 \\
\hline & & & Hyperthymic & 2.560 & 0.477 & 0.000 \\
\hline & & & Irritable & -2.452 & -0.345 & 0.004 \\
\hline
\end{tabular}

TLE:Temporal Lobe Epilepsy; SF-36: Short Form Health Survey; PF: Physical functioning; RP: role limitation due to physical problems; BP: bodily pain; SF: social functioning; GH: general perception of health; RE: role limitation due to emotional problems; VT: vitality; MH: mental health; ETLE: Extratemporal Lobe Epilepsy; ASMs: Antiseizure medicines; Adj. R²: adjusted R square; Std. coeff $\beta$ : standardized beta regression coefficients.

\section{DISCUSSION}

This study explored the predictors of QOL and examined the relationship among QOL, affective temperaments, depression, anxiety, and clinical characteristics in patients with TLE and ETLE. Previous reports have demonstrated the crucial role of affective temperaments in the prodromal phases and $\mathrm{MDs}^{9,10}$. Higher scores on depressive, cyclothymic, and anxious temperaments were associated with a diagnosis of major depressive disorder ${ }^{10}$. Additionally, individuals with irritable, cyclothymic, and hyperthymic temperaments have a tendency to develop bipolar disease ${ }^{9,17}$. In our study, TLE and ETLE groups had significantly higher scores on the depressive, cyclothymic, irritable, and anxious subscales of TEMPS-A than healthy controls. Similar to our results, Yazıcı et al. have shown that all temperament scores were significantly increased, except the hyperthymic temperaments, in $\mathrm{PWE}^{11}$. In addition, Taycan et al. found that PWE had higher scores on all TEMPS-A subscales ${ }^{12}$. These reports claimed that PWE present temperamental disturbances that can be a potential precursor for the development of MDs. However, no significant differences in TEMPS-A, depression, and anxiety scores were found between the TLE and ETLE groups. Consistent with our results, Sanchez-Gistau et al. compared the prevalence of interictal psychiatric disorders with SCID-I in patients with refractory TLE and ETLE. In that study, the hypothesis that patients with TLE have more psychiatric comorbidities than ETLE was not accepted ${ }^{18}$.
In our study, affective temperaments, except hyperthymic, were negatively correlated with almost all SF-36 subscales. Interestingly, we detected a positive correlation with hyperthymic temperament and some SF-36 subscales in both patient groups. This situation may explain why excessively confident, grandiose, energetic, and expansive patterns of people with hyperthymic temperament have a paradoxical tendency to mark optimistic choices of the SF-36 questionnaire. More importantly, in our regression analysis, depressive, anxious and irritable temperaments showed a predictive role for low QOL of patients with TLE. In addition, in our regression model, predictors of low QOL in patients with ETLE were depressive, anxious, irritable, and hyperthymic temperaments. These results indicate the determinative role of subclinical MDs on QOL.

To our knowledge, no published study has compared QOL and affective temperament profiles among patients with focal epilepsy. Our findings showed that patients with TLE and ETLE had higher scores on the depression and anxiety questionnaire than the healthy group. Similarly, recent epidemiological studies have identified a higher prevalence of psychiatric disorders in PWE than in the general population ${ }^{2,19}$. Approximately, onethird of PWE experience depression or anxiety in their lifetime ${ }^{20}$. PWE have fear of having seizures and difficulties in participating in social groups and feel alone and rejected, which lead to an increase in psychiatric comorbidities. However, our data does not support the prevalent thought about the superiority of TLE on impaired depression and anxiety scales. 
Swinkels et al. emphasized that lateralization and localization do not determine the risk of depression, anxiety, and personality in patients with TLE and ETLE, which is consistent with our results ${ }^{8}$. In a prospective multicenter epilepsy surgery study, Devinsky et al. did not find a relationship between depression and anxiety levels and the side or lobe of the seizure focus prior to surgery ${ }^{21}$. In addition, Sanchez-Gistau et al. studied interictal psychiatric disorders in patients with refractory TLE and ETLE and did not support the hypothesis of temporal lobe's priority in psychiatric disorders ${ }^{18}$. In contrast, previous studies have claimed that patients with TLE are more susceptible to affective disorders than those with ETLE or generalized epilepsy ${ }^{6,22}$. Nevertheless, the effect of temporolimbic hyperconnection in TLE on the development of MDs has been controversial among studies, due to the probable effect of the heterogeneity of seizure classification and methodological approaches.

In our sample, SF-36 subscale scores were lower in patients than in controls, without statistical differences between the TLE and ETLE groups. More importantly, in the linear regression analysis, patients with TLE who had comorbid anxiety, increased seizure frequency, depressive temperament, and depressive symptoms had poorer QOL. Additionally, in patients with ETLE, affective temperamental disturbances, depressive symptoms, and polytherapy were predictive factors of lower QOL. Our results confirmed the important role of psychiatric status, frequent seizures, and ASMs in QOL. In patients with TLE, all SF-36 subscale scores were significantly correlated with depression and anxiety scores. All subscales, except $\mathrm{MH}$, were negatively correlated with seizure frequency. In our study, depressive symptoms and comorbid anxiety were the strongest predictors of QOL in the TLE group. Kutlu et al. compared the SF-36 scores of 60 PWE and 33 healthy people and found a correlation between vitality and increased seizure frequency and variables such as educational status, age at seizure onset, disease duration, ASMs, and types of seizures ${ }^{23}$. Similar to this study, Mutluay et al. revealed that PWE with good treatment response had significantly better scores on the SF-36 ${ }^{24}$. A hospital-based study conducted in the Czech Republic confirmed that seizure frequency, employability, and psychiatric comorbidities are strong predictors of QOL in $\mathrm{PWE}^{25}$. A systematic review from the UK summarized 93 QOL studies found in Medline, Embase, and Cochrane Library databases that were published before July 2010. This review pointed out the associations among seizure frequency, seizure severity, and levels of depression and anxiety with reduced QOL in $\mathrm{PWE}^{26}$. Similar to our report, many studies have shown that comorbid depression and anxiety have stronger effects than demographic and disease-related factors ${ }^{27,28}$. On the contrary, some studies have demonstrated the superiority of clinical factors on QOL.

A hospital-based Chinese study claimed that adverse effects of ASMs had a stronger influence than number of ASMs, depression, and anxiety on poorer $\mathrm{QOL}^{29}$. A hospital-based study from Russia reported that increased seizure frequency was the strongest predictor of QOL ${ }^{30}$. In the MEPSY study, QOL was assessed using the Quality of Life in Epilepsy Inventory (QOLIE)-10 in 702 people with epilepsy from Korea, and the strongest predictor was adverse effects of ASMs, followed by depression, seizure control, anxiety, and household income ${ }^{31}$. However, these studies have compared the determinants of QOL in mixed groups of PWE. Previous reports support our findings that psychiatric status has a stronger effect than disease-related variables on determining $\mathrm{QOL}^{32,33}$. In addition, a number of studies have examined the QOL of patients with refractory TLE and documented a significant association between frequent seizures on poorer $\mathrm{QOL}^{34,35}$. Our results agreed with those of previous studies where frequent seizures predicted poorer QOL in TLE. Dourado et al. used the QOLIE-31 to assess the correlation between seizure-related variables and QOL in patients with TLE, ETLE, and idiopathic generalized epilepsy ${ }^{36}$. They found similar scores among patient groups, and increased seizure frequency was a predictor for worse QOL. Consistent with these results, we found no significant differences in SF-36 scores between patient groups. However, in our regression model, seizure frequency was not a predictive factor of poorer QOL in ETLE. Ertem et al. assessed the effects of psychiatric comorbidity, demographic factors, and clinical features on QOL in patients with mesial temporal lobe epilepsy, juvenile myoclonic epilepsy, and healthy controls using the QOLIE-89. In their report, only psychiatric comorbidity in PWE affected QOL regardless of seizure syndrome ${ }^{37}$. Similar to our study, Chen et al. explored the predictive factors of QOL in patients with TLE using the QOLIE-31 inventory ${ }^{38}$.In their study, depression, anxiety, long epilepsy duration, and adverse effects of ASMs were significant predictors for lower QOL. Previous studies that investigated QOL in TLE have controversial results. This difference may be related to the variability in sample size, psychiatric evaluation, methodological process, and heterogeneity of QOL tests.

In psychiatric practice, ASMs have mood-stabilizer and anxiolytic potentials in addition to their antiseizure effect. The beneficial effect of ASMs on QOL and MDs has been well established in $\mathrm{PWE}^{39}$. Nevertheless, many studies have reported that polytherapy and side effects of ASMs can lead to impaired QOL $^{29,38}$. In our sample, the number of ASMs was correlated with worse general health in patients with TLE, whereas a significant correlation was detected in all SF-36 subscales, except physical functioning in ETLE. In the linear regression analysis, the number of ASMs in the ETLE group had a negative predictive role on the physical subscale of SF-36. Further studies are needed to elucidate the effect of ASMs on QOL in patients with focal epilepsy.

This study had several limitations. First, our study was carried out in a single center with a relatively small sample from a tertiary care hospital. Second, we classified seizures based on the International League Against Epilepsy 1989 criteria, which is a noninvasive tool for the localization and lateralization of epilepsy ${ }^{13}$. Third, we did not consider the type of ASMs and time interval between seizures, which might interfere with behavioral and cognitive changes. Fourth, participants were not 
assessed using the $\mathrm{SCID}^{40}$. Finally, our study included nonrandomized patients, which might have biased the results due to the selection of individuals who possibly have better cognition and QOL. Thus, further studies with larger groups are needed to assess predictive factors of QOL in different epilepsy types.

Our study has several strengths. To our knowledge, this is the first study that investigated affective temperaments, disease characteristics, and psychiatric status as possible predictors of QOL in patients with TLE and ETLE. Previous studies have assessed affective temperaments only in patients with mixed types of epilepsy. Second, our study provides a new insight into subclinical manifestations of MDs in focal epilepsy. Third, all questionnaires were validated and applied by an experienced psychiatrist.

In conclusion, affective temperamental disturbances, comorbid psychiatric disorders, and disease-related variables can affect the QOL of patients with TLE and ETLE. An important but overlooked topic is the negative effect of affective temperaments. From a clinical perspective, our findings suggest that evaluating factors that may impair QOL in patients with different epilepsy types can improve treatment strategies for subclinical MDs and comorbid psychiatric disorders.

\section{REFERENCES}

1. Sirven JI. Epilepsy: a spectrum disorder. Cold Spring Harb Perspect Med. 2015 Sep 1;5(9):a022848. https://doi.org/10.1101/cshperspect. a022848

2. Hermann BP, Seidenberg M, Bell B. Psychiatric comorbidity in chronic epilepsy: identification, consequences, and treatment of major depression. Epilepsia. 2000 Feb;41 Suppl 2:S31-41. https://doi. org/10.1111/j.1528-1157.2000.tb01522.x

3. Kanner AM. Mood disorder and epilepsy: a neurobiologic perspective of their relationship. Dialogues Clin Neurosci. 2008;10(1):39-45. https://doi.org/10.31887/DCNS.2008.10.1/amkanner

4. Mula M, Sander JW. Psychosocial aspects of epilepsy: a wider approach. BJ Psych Open. 2016 Aug 17;2(4):270-4. https://doi. org/10.1192/bjpo.bp.115.002345

5. Mahrer-Imhof R, Jaggi S, Bonomo A, Hediger H, Eggenschwiler P, Krämer $\mathrm{G}$, et al. Quality of life in adult patients with epilepsy and their family members. Seizure. 2013 Mar 1;22(2):P128-35. https://doi. org/10.1016/j.seizure.2012.11.012

6. Perini Gl, Tosin C, Carraro C, Bernasconi G, Canevini MP, Canger R, et al. Interictal mood and personality disorders in temporal lobe epilepsy and juvenile myoclonic epilepsy. J Neurol Neurosurg Psychiatry. 1996 Dec 1;61(6):601-5. https://doi.org/10.1136/ jnnp.61.6.601

7. Kondziella D, Alvestad S, Vaaler A, Sonnewald U. Which clinical and experimental data link temporal lobe epilepsy with depression? J Neurochem. 2007 Dec;103(6):2136-52. https://doi.org/10.1111/ j.1471-4159.2007.04926.x

8. Swinkels WAM, van Emde Boas W, Kuyk J, van Dyck R, Spinhoven P. Interictal depression, anxiety, personality traits, and psychological dissociation in patients with temporal lobe epilepsy (TLE) and extraTLE. Epilepsia. 2006 Dec;47(12):2092-103. https://doi.org/10.1111/ j.1528-1167.2006.00808.x

9. Akiskal KK, Akiskal HS. The theoretical underpinnings of affective temperaments: implications for evolutionary foundations of bipolar disorder and human nature. J Affect Disord. 2005 Mar;85(1-2):231-9. https://doi.org/10.1016/j.jad.2004.08.002

10. Akiskal HS, Akiskal KK, Haykal RF, Manning JS, Connor PD. TEMPS-A progress towards validation of a self-rated clinical version of the Temperament Evaluation of the Memphis, Pisa, Paris, and San Diego Autoquestionnaire. J Affect Disord. 2005 Mar;85(1-2):3-16. https:// doi.org/10.1016/j.jad.2004.12.001

11. Yazici E, Yazici AB, Aydin N, Orhan A, Kirkpinar I. Affective temperaments in epilepsy. Psychiatry Clin Psychopharmacol. 2012;22(3):254-61. https://doi.org/10.5455/bcp.20120731060406

12. Taycan SE, Taycan O. Affective temperament profiles and clinical correlates in patients with epilepsy: a link from mood disorders. J Affect Disord. 2014 Aug;164:1-4. https://doi.org/10.1016/j. jad.2014.03.030
13. Commission on classification and terminology of the International League Against Epilepsy. Proposal for revised classification of epilepsies and epileptic syndromes. Epilepsia. 1989 Aug;30(4):38999. https://doi.org/10.1111/j.1528-1157.1989.tb05316.x

14. Beck AT, Ward CH, Mendelson M, MockJ, Erbaugh J. An inventory for measuring depression. Arch Gen Psychiatry. 1961 Jun;4:561-71. https://doi.org/10.1001/archpsyc.1961.01710120031004

15. Beck AT, Epstein N, Brown G, Steer RA. An inventory for measuring clinical anxiety: psychometric properties. J Consult Clin Psychol. 1988 Dec;56(6):893-7. https://doi.org/10.1037/0022-006X.56.6.893

16. Ware Jr JE, Gandek B. Overview of the SF-36 health survey and the international quality of life assessment (IQOLA) project.J Clin Epidemiol. 1998 Nov 1;51(11):P903-12. https://doi.org/10.1016/ S0895-4356(98)00081-X

17. Serafini G, Geoffroy PA, Aguglia A, Adavastro G, Canepa G, Pompili $M$, et al. Irritable temperament and lifetime psychotic symptoms as predictors of anxiety symptoms in bipolar disorder. Nord J Psychiatry. 2018 Jan;72(1):63-71. https://doi.org/10.1080/08039488.2017.1385 851

18. Sanchez-Gistau V, Pintor L, Sugranyes G, Baillés E, Carreño M, Donaire A, et al. Prevalence of interictal psychiatric disorders in patients with refractory temporal and extratemporal lobe epilepsy in Spain. A comparative study. Epilepsia. $2010 \mathrm{Jul}$ 1;51 (7):1309-13. https://doi.org/10.1111/j.1528-1167.2009.02464.x

19. Rai D, Kerr MP, McManus S, Jordanova V, Lewis G, Brugha TS. Epilepsy and psychiatric comorbidity: a nationally representative populationbased study. Epilepsia. 2012 Jun; 53(6):1095-103. https://doi. org/10.1111/j.1528-1167.2012.03500.x

20. Kwon O-Y, Park S-P. Depression and anxiety in people with epilepsy. J Clin Neurol. 2014 Jul 3;10(3):175-88. https://doi.org/10.3988/ jcn.2014.10.3.175

21. Devinsky O, Barr WB, Vickrey BG, Berg AT, Bazil CW, Pacia SV, et al. Changes in depression and anxiety after resective surgery for epilepsy. Neurology. 2005 Dec 13;65(11):1744-9. https://doi. org/10.1212/01.wnl.0000187114.71524.c3

22. Quiske A, Helmstaedter C, Lux S, Elger CE. Depression in patients with temporal lobe epilepsy is related to mesial temporal sclerosis. Epilepsy Res. 2000 Apr;39(2):121-5. https://doi.org/10.1016/S09201211(99)00117-5

23. Kutlu A, Bașaran S, Altun N, Unalan H, Komsuoğlu SS. Quality of life, depression and anxiety in patients with epilepsy: controlled study with Short Form 36 questionnaire, beck depression inventory and Hamilton Anxiety Scale. Neurosurg Q. 2010 Jun;20(2):95-9. https:// doi.org/10.1097/wnq.0b013e3181dcb4ce

24. Mutluay FK, Gunduz A, Tekeoglu A, Oguz S, Yeni SN. Health related quality of life in patients with epilepsy in Turkey. J Phys Ther Sci. 2016 Jan;28(1):240-5. https://doi.org/10.1589/jpts.28.240 
25. Tlusta E, Zarubova J, Simko J, Hojdikova H, Salek S, Vljek J. Clinical and demographic characteristics predicting QOL in patients with epilepsy in the Czech Republic: how this can influence practice. Seizure. 2009 Mar 1;18(2):P85-9. https://doi.org/10.1016/j. seizure.2008.06.006

26. aylor RS, Sander JW, Taylor RJ, Baker GA. Predictors of health-related quality of life and costs in adults with epilepsy: a systematic review. Epilepsia. 2011 Dec;52(12):2168-80. https://doi.org/10.1111/j.15281167.2011.03213.x

27. Kwan P, Yu E, Leung H, Leon T, Mychaskiw MA. Association of subjective anxiety, depression, and sleep disturbance with quality-of-life ratings in adults with epilepsy. Epilepsia. 2009 May 7;50(5):1059-66. https://doi.org/10.1111/j.1528-1167.2008.01938.x

28. Milovanović M, Martinović Ž, Tošković O. Determinants of quality of life in people with epilepsy in Serbia. Epilepsy Behav. 2014 Feb 1;31:P160-6. https://doi.org/10.1016/j.yebeh.2013.12.015

29. Yue L, Yu P-M, Zhao D-H, Wu D-y, Zhu G-X, Wu X-Y, et al. Determinants of quality of life in people with epilepsy and their gender differences. Epilepsy Behav. 2011 Dec 1;22(4):P692-6. https://doi.org/10.1016/j. yebeh.2011.08.022

30. Melikyan E, Guekht A, Milchakova L, Lebedeva A, Bondareva I, Gusev E. Health related quality of life in Russian adults with epilepsy: the effect of socio-demographic and clinical factors. Epilepsy Behav. 2012 Dec 1;25(4):P670-5. https://doi.org/10.1016/j. yebeh.2012.09.042

31. Lee S-J, Kim J-E, Seo J-G, Cho YW, Lee J-J, Moon H-J, et al. Predictors of quality of life and their interrelations in Korean people with epilepsy: a MEPSY study. Seizure. 2014 Oct;23(9):762-8. https://doi. org/10.1016/j.seizure.2014.06.007

32. Lee S-J, Kim J-E, Seo J-G, Cho YW, Lee J-J, Moon H-J, et al. Predictors of quality of life and their interrelations in Korean people with epilepsy: a MEPSY study. Seizure. 2014 Oct 1;23(9):P762-8. https:// doi.org/10.1016/j.seizure.2014.06.007
33. Boylan L, Flint LA, Labovitz DL, Jackson SC, Starner K, Devinsky O. Depression but not seizure frequency predicts quality of life in treatment-resistant epilepsy. Neurology. 2004 Jan 27;62(2):258-61. https://doi.org/10.1212/01.WNL.0000103282.62353.85

34. Pulsipher DT, Seidenberg M, Jones J, Hermann B. Quality of life and comorbid medical and psychiatric conditions in temporal lobe epilepsy. Epilepsy Behav. 2006 Nov 1;9(3):P510-4. https://doi. org/10.1016/j.yebeh.2006.07.014

35. Chou C-C, Shih Y-H, Yen D-J, Kwan S-Y, Yu H-Y. Long-term healthrelated quality of life in drug-resistant temporal lobe epilepsy after anterior temporal lobectomy. Epileptic Disord. 2015 Jun;17(2):177-83. https://doi.org/10.1684/epd.2015.0744

36. Dourado MV, Alonso NB, Martins HH, Oliveira ARC, Vancini RL, de Lima C, et al. Quality of life and the self-perception impact of epilepsy in three different epilepsy types. J Epilepsy Clin Neurophysiol. 2007 Dec;13(4):191-6. https://doi.org/10.1590/S1676-26492007000400009

37. Ertem DH, Dirican AC, Aydın A, Baybas S, Sözmen V, Ozturk M, et al. Exploring psychiatric comorbidities and their effects on quality of life in patients with temporal lobe epilepsy and juvenile myoclonic epilepsy. Psychiatry Clin Neurosci. 2017 Apr;71(4):280-8. https://doi. org/10.1111/pcn.12499

38. Chen Y-Y, Huang S, Wu W-Y, Liu C-R, Yang X-Y, Zhao H-T, et al. Associated and predictive factors of quality of life in patients with temporal lobe epilepsy. Epilepsy Behav. 2018 Sep 1;86:85-90. https:// doi.org/10.1016/j.yebeh.2018.06.025

39. Kalogjera-Sackellares D, Sackellares JC. Improvement in depression associated with partial epilepsy in patients treated with lamotrigine. Epilepsy Behav. 2002 Dec 1;3(6):P510-6. https://doi.org/10.1016/ S1525-5050(02)00528-0

40. First MB, Spitzer RL, Gibbon M, Williams JBW. Structured clinical interview for DSM-IV clinical version (SCID-I/CV). Washington (DC): American Psychiatric Press, Inc; 1996. 